\title{
El derecho a no ser discriminado o a vivir como iguales
}

\author{
The Right Not to be Discriminated Against or to Live \\ as Equals
}
0 direito a não ser discriminado ou a viver como iguais

Ana Morell Sanz

A Olivia

Fecha de recepción: 30 de junio de 2016

Fecha de aprobación: 6 de enero de 2017

Doi: http://dx.doi.org/10.12804/revistas.urosario.edu.co/anidip/a.5672

Para citar este artículo: Morell Sanz, A. (2 017).El derecho a no ser discriminado o a vivir como iguales. Anuario Iberoamericano de Derecho Internacional Penal - ANIDIP, 5, 94-120, doi: http://dx.doi.org/10.12804/ revistas.urosario.edu.co/anidip/a.5672

\section{Resumen}

Este trabajo es resultado de la creencia de que el origen de gran parte de los males actuales que infligen a la humanidad tiene su raíz en la discriminación. En este artículo se lleva a cabo una fundamentación de los Derechos Humanos en el derecho a no ser discriminado como principio moral sustantivo y su necesaria traducción en un principio procedimental discursivo no discriminatorio, que articulará el foro en el que concreta un catálogo de derechos, sin olvidar tener en cuenta las razones proporcionadas por las potencialidades humanas básicas a satisfacer.

Palabras clave: Derechos Humanos, derecho a no ser discriminado,

fundamentación de derechos.

\section{Abstract}

This work is the result of the belief that the origin of many of the evils currently suffered by humanity has its roots in the discrimination. The article elaborates on a human rights foundation based on the right not be discriminated as a moral principle, which turns necessarily into a non-discriminatory discursive procedural principle. The latter will generate a forum in which a catalog of rights can be

\footnotetext{
* Doctora y magíster en Derecho, Universidad Alberto Hurtado (Chile).
} 
developed. All of this should take place taking into account the reasons provided by the basic human potentialities to be satisfied.

Keywords: Human Rights, right not to be discriminated, foundation of rights.

\section{Resumo}

Este trabalho é resultado da crença de que a origem de grande parte dos males atuais que infligem à humanidade tem a sua raiz na discriminação. No mesmo leva-se a cabo uma fundamentação dos direitos humanos no direito a não ser discriminado como princípio moral substantivo e a sua necessária tradução em um princípio procedimental discursivo não discriminatório, que articulará o foro no qual concretar um catálogo de direitos, sem esquecer de tomar em conta as razões proporcionadas pelas potencialidades humanas básicas a satisfazer.

Palavras-chave: Direitos Humanos, Direitos a Não Ser Discriminado,

Fundamentação de Direitos.

\section{Introducción}

El objetivo del presente artículo es justificar la fundamentación de la idea de derechos $^{1}$ en el igual reconocimiento de todos los seres humanos y en el no ser discriminados como ideal moral.

El interés de este enfoque reside en la estrecha relación que existe entre discriminación y comisión de crímenes internacionales ${ }^{2}$ y/o violación de los derechos humanos, $^{3}$ en la actualidad de estos fenómenos. Hoy se afirma respecto a los crímenes

$1 \quad$ Siguiendo a Rodríguez-Toubes (1995), por idea de derechos entiendo la idea abstracta de Derechos Humanos: "cuando me refiero al fundamento de los derechos humanos estoy aludiendo a sus raíces últimas, las cuales se asocian no tanto al catáloğo de derechos positivizados en los textos internacionales como a la idea de Derechos Humanos en la que, a su vez, se basa este catáloğo (...). Sólo este núcleo (...) es susceptible de una fundamentación unitaria" (p. 34). Utilizado con el mismo sentido, ver Laporta (1987, p. 23). Sobre la posibilidad y necesidad de fundamentar los derechos, ver Junquera (2002, pp. 400-407).

2 El delito internacional de persecución consiste, según lo establecido por el Estatuto de la Corte Penal Internacional, en la "privación intencional y ģrave de derechos fundamentales (...) en razón de la identidad del ģrupo [atacado]" o debido a razones "políticas, raciales, nacionales, étnicas, culturales, reliģiosas, de genero (...) u otros motivos (...) inaceptables" (United Nations, U.N. Doc.A/CONF.183/9*, 1998, Art. 7.1 (h) y $7.2(\mathrm{~g}))$. Se trata, por lo tanto, de un delito cometido por razones discriminatorias. Por otra parte, el Proyecto de Código de Delitos Contra La Paz y La Seguridad de La Humanidad (International Law Commission, ILC (Sess. 48) (A/48/10), 1996, Art 18) reconoce que la comisión del delito de persecución se produce a través de la comisión de otros crímenes internacionales. Cabe así afirmar que la discriminación guuarda una estrecha relación con la comisión de delitos internacionales. Estas conductas discriminatorias, hoy delitos, han ocurrido desde el principio de la historia de la Humanidad con una sorprendente similitud en su modus operandi. Ver Naimark (2001, p. 5) y Vega Franco (1984, p. 137). Bobbio (1994), en un análisis de cómo nacen y evolucionan los prejuicios, afirma "quien conozca un poco la historia sabe que siempre han existido prejuicios nefastos y que también cuando alģuno de estos es superado surģen rápidamente otros” (p. 173).

3 Ya en 1993, la Declaración sobre la Eliminación de la Violencia contra la mujer de la Organización de las Naciones Unidas (A.G. res. 48/104, 1993), delimitó esta violencia como todo acto de violencia basado en la pertenencia al sexo femenino. Un año después la Recomendación 19 del CEDAW (U.N. Doc. HRI/GEN/1// 
internacionales cometidos por motivos discriminatorios que "el reconocer la existencia de grupos diversos dentro de unas fronteras comunes sin comprometer la capacidad del Estado de gobernar a su población, está emergiendo como uno de los problemas más graves en el mundo de la postguerra fría” (Ku \& Diehl, 1998, p. 10), ${ }^{4}$ mientras que la comunidad internacional advierte muy preocupada que las violaciones de derechos discriminatorios son una pandemia (United Nations High Commissioner for Human Rights, 2012).

Para fundamentar la idea de derechos en el igual reconocimiento de todos los seres humanos se necesita, en primer lugar, concebir el derecho a no ser discriminado como un derecho, según Laporta (1987), "que (...) está antes que (...) los poderes normativos, (...) [que es] la razón que se presenta como justificación de la existencia de (...) normas" (p. 28). En sintonía con lo expresado por Laporta sobre el derecho, Calsamiglia (1989) define los principios como "razones justificativas que no se miden por la forma de su edición ni por su origen, sino por su fuerza argumentativa” (p. 99), ${ }^{5}$ como también señala el Profesor Ávila (2011, pp. 70 y ss).

Rev.l (1994), estableció que la definición de discriminación de la Convención contra la Discriminación de la Mujer comprendía la violencia contra la mujer en todas sus formas y la Oroganización de Estados Americanos (OEA) adoptó la Convención Interamericana para Prevenir, Sancionar y Erradicar la Violencia contra la Mujer o "Convención Belém do Pará" (OEA, 1994). Desde entonces los instrumentos e iniciativas universales y reģionales sobre la materia no han dejado de sucederse y reflejan una preocupación uniforme sobre la ģravedad del problema de la violencia contra la mujer, su relación con la discriminación históricamente sufrida que la perpetúa, y la imperiosa necesidad de adoptar estrateģias integrales para erradicarlas. Concretamente, a nivel reģional se ha avanzado mucho durante las dos últimas décadas. Así, en noviembre de 2005 entraba en vigor el Protocolo Adicional a la Carta Africana sobre los Derechos Humanos y de los Pueblos sobre los Derechos de la Mujer en África, adoptado por la Unión Africana en 2003 (AU, 2005). El Consejo de Europa, por su parte, adoptaba la Recomendación 2002 (5) obligando a sus Estados a tomar una acción integral contra la violencia de género y lanzaba una campaña con idéntico propósito de noviembre de 2006 a junio de 2008 (CM/Rec. (2002) 5) En sentido similar, el Consejo Ministerial de la Orģanización de Seguridad y Cooperación Europea adoptaba Decisiones que contenían prescripciones e iniciativas contra la violencia machista (OSCE, MC. DEC 15/05). En 2002 entraba en vigor un tratado sobre los derechos de mujeres de la Asociación de Cooperación Reģional de Asia Meridional (SAARC, 2002). En 2004, la OEA creaba un mecanismo para la supervisión del cumplimiento de la "Convención Belém do Pará". En 2011, bajo los auspicios del Consejo de Europa, se adoptó el Convenio Europeo sobre Prevención y Lucha contra la Violencia contra las Mujeres y la Violencia Doméstica que define, en su artículo 3, la violencia contra las mujeres como "una violación de los derechos humanos y una forma de discriminación... una violencia basada en el género", (CETS, 2011). La UE hizo suya la definición de violencia contenida en la Declaración sobre la Eliminación de la Violencia contra la mujer de la ONU de 1993 y considera amparada la prohibición de esta violencia en los artículos 7 y 23 de la Carta de Derechos Fundamentales de la Unión (CE, 2000).

4 De forma similar, el Profesor Roldán (2008) afirma "se entiende...que la paz y la seguridad internacionales se vean comprometidas mayoritariamente a raíz de conflictos orioginariamente internos” (p. 17).

5 En este trabajo se asume la anterior concepción de los derechos o principios, es decir, se conciben como razonamientos de normas y no como su consecuencia, pasando por alto que la terminoloǵía utilizada para referirse a los derechos y a los principios, así como las concepciones a las que éstas responden, no son unívocas. Por ejemplo, el texto constitucional español se refiere a los derechos como Derechos Humanos, constitucionales, fundamentales, y libertades públicas y libertades fundamentales. Asimismo, existen diferentes concepciones de lo que es un derecho subjetivo y de si los derechos, en base a su función, son valores (Pérez Luño), principios (Zagrebelsky, Alexy, Prieto), instituciones, institutos 
Por tanto, se puede plantear el derecho/principio de no discriminación como justificación de normas, no vinculando su exigibilidad a su tipificación o a las garantías jurídicas otorgadas por el ordenamiento positivo. ${ }^{6}$

En segundo lugar, es necesaria la adopción de un paradigma del Derecho de carácter dialógico, consensual, procedimental y contrafáctico. La elección de este paradigma reside en su virtualidad crítica de la realidad y en su valor justificador que se aleja de otros paradigmas como el metafísico iusnaturalista o el individualista solipsista.

El paradigma adoptado presupone la asunción de un principio de justicia que se concreta en la igualdad de estatus y en el derecho a no ser discriminado. Ambos conceptos, son constitutivos de la acción moral del sujeto -su violación implica un daño universalizable, o presente, siempre que se produce la violación del derecho-, y por tanto podrían considerarse razón suficiente para fundamentar los derechos, que deberán concretarse de acuerdo a un procedimiento informado por este principio de justicia: el procedimiento discursivo consensual. La igualdad de estatus o el derecho a no ser discriminado es lo que posibilita la existencia y funcionamiento del sistema que propugna este paradigma, y se presenta como un presupuesto lógico para que el debate público en torno a los derechos sea posible. Esta afirmación, que trataré de justificar en estas páginas, esconde otra: la concepción a priori del ser humano como sujeto moral cuyo fin último es vivir una vida elegida autónomamente.

En otras palabras, el presente artículo defiende una fundamentación de los Derechos Humanos cuyo principio moral sustantivo o idea reguladora es el trato no discriminatorio o de la igualdad de estatus de todos seres humanos, y necesariamente, su traducción en un principio procedimental discursivo no discriminatorio, que articulará el foro en el que se concreta un catálogo de derechos, sin olvidar tener en cuenta las razones proporcionadas por las potencialidades humanas básicas a satisfacer. ${ }^{7}$

(Peces-Barba) o reģlas. Respecto a la diversidad terminológica presente en la Constitución Española y en el orden mencionado, ver Constitución Española, (CE, Preámbulo, Art. 149, Arts. 10.2, 25.2, 27.2, 81, 94, y Tit. I, Cap. IV, Art. 13, Tit. I, Cap. II, Secc. I, Art. 81, Art. 27.2, y Tit. I, Cap. IV, respectivamente). Sobre alģunas de las distintas concepciones existentes de derecho subjetivo, Alexi, (Alexi, 1993, pp.173-186, 203-210, y 219); Respecto a las distintas concepciones de los derechos en su función objetiva, ver Barranco (Barranco, 2000, pp. 123-185), Alexi, (Alexi, 1993, pp. 63-80, 138-147, 243-245, 271-276 y 507-509), y Zağrebelsky, (Zagrebelsky 1995, pp. 16, y 109-126).

6 Ver objeciones de Boeckenfoerde (Boeckenfoerde, 1991, pp. 185 y ss.) y Habermas (Habermas, 1996) a esta comprensión.

7 Las variadas formas de fundamentar los derechos se han sintetizado en fundamentaciones histórico-sociológicas, racionales-teóricas (iusnaturalistas, axiológicas), etc., ver De Castro Cid y Escalopa Martínez (1997, pp. 213-215) y Pérez Luño (1989, pp. 279-288). 


\section{El principio/derecho a no ser discriminado}

El derecho a no ser discriminado está reconocido en numerosos instrumentos internacionales ${ }^{8}$ y constituciones estatales. ${ }^{9}$ Además, en muchos países la Constitución o la ley prevén recursos judiciales específicos ante la violación del principio de no discriminación (Austria), o consideran como un delito la incitación a la discriminación (Suecia, Dinamarca, Finlandia, Polonia, Rumania, Níger), y/o crean órganos especiales de carácter administrativo para identificar las violaciones de este derecho (Australia, Austria, Bélgica, Canadá, Alemania, Finlandia, Hungría, India, México, Nueva Zelanda, Noruega, Filipinas, Rumania, Singapur, Suecia, EE.UU.) (Cfr Capotorti, 1991 y Morell, 2010).

Este reconocimiento constitucional adopta varias formas. Puede incluirse una cláusula que prohíbe la discriminación en el reconocimiento del disfrute de los derechos y libertades; pueden prohibirse determinadas modalidades o tipos de acciones discriminatorias, en ámbitos específicos o por determinadas razones; se puede equiparar la no discriminación al derecho a la propia personalidad, o se puede prohibir toda discriminación (siendo ésta no reconducible exclusivamente al disfrute no discriminatorio de los derechos reconocidos por las mismas). ${ }^{10}$ Valga como ejemplo de este último tipo de reconocimiento constitucional, el de la constitución polaca, que

Ver la Convención Internacional sobre la Eliminación de todas las Formas de Discriminación Racial (ONU, 1969), la Convención sobre la Eliminación de todas las Formas de Discriminación contra la Mujer (ONU, 1981), la Declaración sobre la Eliminación de todas las formas de Intolerancia y Discriminación fundadas en la Reliģión o las Convicciones (ONU, 1981), el Convenio sobre la Discriminación -Empleo y Ocupación- (Orģanización Internacional del Trabajo, 1960) y la Convención relativa a la lucha contra las Discriminaciones en la Esfera de la Enseñanza (Oroganización de las Naciones Unidas para la Educación, la Ciencia y la Cultura, 1960).

9 Las constituciones de los países que se enumeran a continuación, prohíben o declaran inconstitucional o ilegal las discriminaciones en el disfrute de todos o de algunos de los derechos reconocidos por las mismas: Alemania (Grundggesetz, Art. 3(3)), Arģentina (Parte I, Cap.I, Sec. 43, (2)), Austria (Bundes-Verfassungsgosetz, Art. 7), Bahamas (Art. 26,(1)(2)(3)(7)(8)), Barbados (Cap.III, 23.1 (a), (b), 23.2, 23.3, 23.4), Bielorrusia (Proyecto de constitución, Art. 22), Bélģica (Arts. 10 y 11), Bolivia (Art. 6), Brasil (Art. 3. IV, Art. 5.XLI), China (Arts. 34 y 36(2)), Colombia (Arts. 5 y 13), Costa Rica (Arts. 33 y 68), Croacia (Art. 14 (1)), Cuba (Introducción y Arts. 42 y 43), Chipre (2), Ecuador (Arts. 17 y 23.3), El Salvador (Art.6), España (Arts. 14 y 35), Eslovaquia (3), Etiopía (Art.25), Francia (Preámbulo, Art. 1), Guayana (Arts. 29 (1), 30, y 40 (1)), Haití (Preámbulo y Art.19), Holanda (Art. 1), Honduras (Art. 60), India (Apéndice I, (4) (b)), Italia (Art.3), Irak (Art. 19(a)), Irlanda (Art. 40, 1, 6 (2)), Jamaica (Cap. III, 24, (1),(2), (3)), Japón (Art.14 (1)), Lituania (Art.29), Macedonia (Arts. 9(1) y 110), México (Art. 1), Panamá (Art.19), Paraguaay (Art. 46 (1)), Perú (Art.2), Portuģal (Art.13 (2)), Federación Rusa (Art. 19. (2)(3)), Singapur (Art.5 (2)), Trinidad y Tobagoo (Art.4), Uruguay (Art. 8), y Venezuela (Preámbulo y Arts. 19 y 21(1)). Ver Capotorti (Cfr Capotorti, 1991, pp. 93-97) y Morell (Morell, 2010, pp. 241 y ss.).

10 Para esta variedad de reconocimiento constitucional, ver el artículo primero de la Constitución eslovaca que declara inconstitucional cualquier incitación a la discriminación; la Constitución estadounidense, (Enmienda 14, Art. 15 (1) que reconoce el derecho al sufraģio no discriminatorio), la Constitución de Madaģascar (que ģarantiza el sufraģio pasivo no discriminatorio (Art.1)), y la Constitución de Fiji (que asegura el acceso a la educación no discriminatoria (Secc. 3)); la Constitución estadounidense, (Enmienda 14, Art.19 (1)) prohibiendo la discriminación por razón de sexo e iģual la Constitución de Mongoolia (Art. 14 (2)), (Morell, 2010, pp. 241 y ss.). 
establece que "nadie podrá ser discriminado en el ámbito político, social o económico por ninguna razón". ${ }^{11}$ Este último tipo de reconocimiento parece el más acertado, ya que no contempla el derecho a no ser discriminado como un derecho subjetivo de sujetos aislados (o de su autonomía privada), sino como un derecho de sujetos que interactúan en la esfera pública (contemplando su autonomía política, social o económica, o su participación en la constitución del espacio público). Como afirma Habermas (1998), "es la interacción socializadora la que ha de constituir el punto de referencia del análisis del desarrollo del yo" (p. 550)..$^{12}$ De esta forma, el principio/ derecho a no ser discriminado cobra sentido con la interacción social de los sujetos.

El contenido de este principio consiste en la igual y, por tanto, inclusiva consideración y participación de todos en la construcción del espacio público. Es decir, en la igual libertad de todos en la decisión que constituye los criterios base de la sociedad.

A continuación, se introducen unas precisiones respecto a la relación que guarda el derecho a no ser discriminado con los principios de igualdad y libertad. También se valoran las propuestas ideales de Rawls y Habermas, que nos permiten establecer esta relación, sin dejar de observar el mundo real. ${ }^{13}$

Respecto al principio de igualdad, ${ }^{14}$ tras ofrecer una clasificación de los distintos conceptos de igualdad, de sus características y de su concepción en distintas

11 Ver la Constitución polaca, Art. 32 (2). Similar formulación en la Constitución nicaragüense (Art. 27), y en la Constitución de Surinam (Art. 8.1), (Morell, 2010, pp. 241 y ss.).

12 Además, Habermas concibe los derechos subjetivos como relación intersubjetiva de reconocimiento de libertades de acción por sujetos cooperantes jurídicamente sancionados (Habermas, 1998, p. 153).

13 En adición a las razones señaladas en el texto, inclinarse por la construcción habermasiana se debe a que la concepción antropolóģica que asume y subyace a su razonamiento se considera aquí más realista. Parece concebible que los sujetos reales evalúen subjetivamente y elijan racionalmente (es decir, de acuerdo a su propio interés o utilidad, tal y como cada uno entienda esto último), un proyecto vital común viable. Si bien lo anterior significa creer posible que los sujetos ostenten un potencial discursivo-racional que permita la modificación de sus propias convicciones, esta presunción parece más factible, que el concebir que los sujetos puedan desprenderse de sus peculiaridades, neutralizándose a ellos mismos, ya que no se vislumbra cómo o de acuerdo a qué criterios los sujetos pueden ponderar o decidir qué resulta justo. A lo anterior se añade la creencia en que el respeto a los derechos y a la orģanización socio-política que sustentan, no es una cuestión de tipificación de derechos, sino de la interiorización social de sus siǵnificados o convicción social. Esta interiorización es sinģular, particular o histórica. Respecto a la determinación cultural del hombre, Lukes (1975) afirma "los hombres no nacen libres e iguales (...) sino en una riquísima y extraordinariamente compleja red de 'preceptos' y 'prejuicios', costumbres y tradiciones, de donde obtienen seguridad, disciplina y un siǵnificado para sus vidas", (p. 107). Sobre los criterios de convivencia colectiva como la auténtica clave para el respeto a los derechos, el profesor Bertolino (1999) afirma "el futuro de los derechos del hombre pasa por la progresiva toma de conciencia de las 'buenas razones' que los justifican” (p. 134). En el mismo sentido, el Profesor Vargas-Machuca (2002) sostiene "el futuro de la democracia depende de que los ciudadanos estimen que la democracia importa porque importan sus principios, interioricen un mayor sentido social (...)y se haģan cargo de las consecuencias de lo que en común se decide" (p. 15).

14 La formulación clásica de la iggualdad en Alexy (1993) y Zuñiģa Fajuri, Ağuilera Bertucci, y Vásquez Bravo (2007, pp. 15 y ss.). 
sociedades como las esclavistas o estamentales, las conservadoras, las anarquistas o las comunistas, Atienza (2001) afirma que "la idea de justicia ha ido casi siempre unida a la de igualdad, pero eso no debe llevar a pensar que la 'igualdad' se haya entendido siempre de la misma manera" (pp. 173 y ss).

El derecho a la igualdad de estatus o a no ser discriminado se construye sobre una concepción del hombre como sujeto histórico y culturalmente determinado. No se apela, por tanto, a una concepción de igualdad que confisca diferencias y se justifica privando a los sujetos discursivos de su particularidad. Por este tipo de igualdad entiendo la establecida por el Rawls (1995) de Una teoría de la justicia en la posición original, donde los sujetos no saben qué lugar ocupan en la sociedad, ni cuál es su clase o estatus social, ni qué suerte han tenido en la distribución de talentos y capacidades naturales, ni cuáles son sus metas e intereses, ni la estructura particular de su psicología, ni la generación a la que pertenecen. ${ }^{15}$ Dworkin (1989) alude también a un consenso basado en una hipótesis de situación originaria. El derecho a no ser discriminado defendido en este trabajo se refiere, por el contrario, al ideal habermasiano de un universalismo sensible a las diversidades. En palabras del propio Habermas (1999), “el respeto recíproco e igual para todos, exigido por el universalismo sensible a las diferencias, quiere una inclusión no niveladora y no confiscadora del otro en su alteridad" (p. 72).

Ciertamente, el Rawls (1993) de Liberalismo Político reinterpreta el experimento mental de la posición original como un método heurístico para sistematizar los principios compartidos en el contexto cultural e históricamente particular de las democracias occidentales contemporáneas. El autor explica que los principios de justicia han de ser legitimados y consensuados por ciudadanos que han de ser "razonables" en el uso de la razón pública. Exigir que los ciudadanos sean razonables es, por supuesto, un requisito normativo, pero resultado de una sistematización de valores ya compartidos por ciudadanos reales y particulares, que han sido socializados en la cultura pública de las presentes democracias occidentales. De esta forma, Rawls abandona radicalmente sus iniciales ambiciones metafísicas y universalistas, supeditando ahora la justificación de su concepción de la justicia al desafío de que ésta sea consensuada por ciudadanos que han sido socializados en el contexto particular de los actuales regímenes democráticos. Esta evolución filosófica crea dificultades a la hora de hacer una interpretación unitaria de la teoría rawlsiana.

15 La igualdad de un hombre idealizado y sin atributos es expresada por Rawls (1995) cuando afirma: "debemos asegurar (...) que las inclinaciones y aspiraciones particulares, así como las concepciones de las personas sobre su bien, no afecten los principios adoptados" (p. 31). 
Por otra parte, en la medida en que la justificación de su teoría parece depender ahora de su legitimación democrática a través de un proceso de deliberación en el que los ciudadanos, sin ser privados de las particularidades resultantes de su socialización, han de desplegar la capacidad discursiva necesaria para participar de la razón pública, el último Rawls parece haber desembocado en una concepción de democracia deliberativa de raigambre habermasiana. Si a esto se añade la dificultad de establecer una interpretación coherente entre el primer y el último Rawls que se acaba de señalar, resulta justificable inclinarse por el paradigma habermasiano. Sin embargo, cabe señalar que este estudio no hace una apropiación acrítica del mismo, ya que se corrige la tesis habermasiana, intentando evidenciar los compromisos sustantivos sobre los que ésta parece descansar.

Cabe señalar que el principio de no discriminación no se identifica con una noción genérica de la libertad, ya que la libertad que al ejercerse no se viera informada por un criterio sustantivo, se convertiría en una libertad voraz no mediada. La libertad debe ser informada por la igualdad. Bobbio (1993), al referirse a la igualdad, se pregunta ¿igualdad entre quiénes e igualdad en qué?, y cuando relaciona la igualdad y la libertad concibe como nexo relevante el que "se confronta allí donde la libertad se considera como aquello en lo que los hombres (...) son o deben ser iguales, de ahí la característica de los miembros de ese grupo de ser 'igualmente libres' o 'iguales en la libertad" (p. 56). De forma similar, Contreras (2000), contemplando la igualdad como igualdad en la libertad de actuación, la concibe como "igualdad en la libertad" o como la "igual libertad para todos" (p. 225 y ss.).

En suma, el derecho/principio de no discriminación o derecho a vivir como iguale ${ }^{16} \mathrm{O}$ a ostentar un estatus igual implica una igual libertad de todos a participar, proponer, cuestionar, y decidir en la constitución de lo social y, con ello, de la vida privada.

A continuación, se presenta el modelo discursivo de Habermas como el más apto para realizar el derecho de no discriminación, y por tanto, como modelo al que aspirar, ya que concibe a los sujetos con sus particularidades, pero siempre dando por hecho que éstos han desarrollado aptitudes discursivas/racionales propias y anteriores. Después, se intenta sostener que éste modelo descansa en un principio sustantivo de no discriminación (y no tan sólo en una exigencia procedimental-racional como sostiene Habermas), y justificar el porqué de este principio sustantivo. ${ }^{17}$

16 La expresión "vivir como iguales" es utilizada por Baker en un libro de ensayos de varios autores con el mismo título (Baker, 2000).

17 Nino objetó la concepción de democracia de Habermas (su formalismo por conducir al populismo moral) y la de Rawls (su constructivismo de bienes primarios carentes de legitimidad discursiva), y propuso su propia concepción de democracia deliberativa; sin embargó, su constructivismo epistemolóǵico excluye 


\section{El sujeto discursivo}

Los seres humanos son agentes morales (Kant, 1957) con capacidad valorativa y de autoperfeccionamiento (Rousseau, 1997); en otras palabras, con conciencia de su propio ser y condición. Esta conciencia de que somos y estamos (el ser y el ser-con o reconocimiento del otro), lleva aparejada un proyecto individual y social (Niebuhr, 2001). El hecho del pluralismo de proyectos, ${ }^{18}$ de concepciones del mundo, implica necesariamente una confrontación y coordinación. ${ }^{19}$ Ésta es la confrontación y racionalización de proyectos en la que ha insistido Habermas.

La coordinación de proyectos, dirá el autor alemán, no es posible sin la coordinación lingüística de la acción. ${ }^{20}$ Ésta última implica que los participantes al hablar pretenderán la validez de sus discursos y asumirán la resolución argumentativa o el reconocimiento intersubjetivo de sus pretensiones, presumiendo que sus ideas se ven respaldadas por los mejores argumentos (universalidad de la aceptabilidad racional). ${ }^{21}$ Así, los que interactúan comunicativamente suponen, en primer lugar, el reconocimiento recíproco de la capacidad de responder de sus propios actos; segundo, que los hablantes participan con fines ilocucionarios; tercero, que el acuerdo se condiciona al reconocimiento intersubjetivo de pretensiones de validez criticables,

del debate unos derechos básicos y cae en falencias por él mismo criticadas a Habermas y Rawls. Acerca de esto ver Montero (2006) y Alexy (2003, pp. 173 y ss.). Lo anterior no quiere decir que se deba desconocer la contribución del principio ético-discursivo a la mejora de la calidad institucional del Estado democrático de derecho, ver Prono (2013).

18 Habermas (1998) afirma que "cuanto más aumenta la complejidad de la sociedad (...), con tanta más fuerza se produce una pluralización de formas de vida y una individualización de las biografías, que hacen que se reduzcan y encojan las zonas de solapamiento o convergencia de las convicciones de fondo que caracterizan el mundo de la vida" (p. 87). Afirmando también que, por tanto, "los nuevos conflictos se desencadenan (...) en torno a cuestiones relativas a la gramática de las formas de vida" (Habermas, 1987, p. 556).

19 De Lucas (1994), ante el relativismo cultural (ético) vigente, afirma que el único camino hacia la universalidad de los Derechos Humanos es construir (lo que presupone confrontar propuestas) o "acordar lo que nos parece más razonable", un "consenso (...) permanentemente inacabado (porque el pluralismo y el conflicto son constitutivos de un sistema abierto)" (p. 113). Este profesor expone también que los conflictos de la multiculturalidad son conflictos de identidades, de reconocimiento y de inclusión (De Lucas, 1996, p. 94).

20 En otras palabras, el empleo del lenguaje orientado a la comprensión de lo que explica "no [es](...) solamente el momento fundador de generalidad que representa la formación de conceptos, sino también el momento transcendedor del tiempo, que representa la formación de juicios verdaderos (...). El mundo como conjunto de hechos posibles se constituye solamente para una comunidad de interpretación cuyos miembros se entienden entre sí sobre algo en el mundo dentro de un mundo de la vida intersubjetivamente compartido (...) la validez ha de entenderse (...) como «validez que se nos impone como tal a nosotros"” (Habermas, 1998, pp. 75-76). Así, la coordinación linguüística permite alcanzar consensos motivados por y para el conjunto de los interpretadores.

21 En el modelo procedimental de leģitimación democrática otorģada mediante la deliberación pública en las sociedades liberales de Habermas, los sujetos dialogan en base a criterios racionales. Al respecto Ackerman señala que este dialoģo es constrictivo, es decir, competitivo y no estrictamente racional, con lo que aporta realismo al modelo habermasiano sin solucionar con ello todos los problemas de su concepción de diáloğo. Ver Monserrat y Abad (2009). 
transcendedoras/normativas y resolubles, y finalmente, están dispuestos a asumir las obligaciones derivadas del consenso alcanzado (base de validez del habla que informará lo construido comunicativamente).

El riesgo de desacuerdo innato al mecanismo de interacción comunicativa (ya que en ésta, todo es tematizable), y el grado de división social que la discrepancia comporta, se minimiza por la inserción de la comunicación en contextos asentados por acuerdos. Estos consensos se alimentaban anteriormente de convicciones familiares no discutidas e instituciones arcaicas sacras, siendo hoy este potencial desintegrador (en sociedades plurales y complejas) neutralizado por Habermas (1998) "la regulación normativa de interacciones estratégicas en la que, o sobre la que, los propios actores pudieran ponerse de acuerdo o entenderse" (p. 89). Estas normas que pueden servir para neutralizar los desacuerdos sobre pretensiones de validez o con fuerza integradora, que informarán y resultarán al tiempo de la interacción comunicativa, conforman el sistema de derechos. (A pesar de la anterior afirmación, se parte de que siguen existiendo consensos previos a los derechos, ya que en caso contrario, la maquinaria discursiva no funcionaría). Sin embargo, el acuerdo sobre los derechos no se asume, sino que es posible porque en la confrontación discursiva se impone la pretensión avalada por el mejor argumento. A la asunción de este principio del discurso o universalidad de la aceptación racional del mejor argumento subyace la creencia de la igualdad discursiva/racional de los sujetos o la participación discursiva no discriminatoria y, de esta presunción (que Habermas concibe como exigencia racional), resulta la legitimidad de los derechos. Es decir, todos participan, y la universalidad de la aceptación racional del mejor argumento permite la confrontación funcional de interacciones estratégicas, resultando pues en la fundamentación discursiva de los derechos.

Así, el principio del discurso informa la propia normativa de la coordinación comunicativa, permitiendo su autocuestionamiento; el disenso es funcional y asumido por el propio sistema jurídico como principio democrático. Habermas (1998) afirma que "la teoría discursiva del derecho entiende, (...) el Estado democrático de derecho como la institucionalización que discurre a través de derecho legítimo (y que, por tanto, garantiza la autonomía privada) de procedimientos y presupuestos comunicativos para una formación discursiva de la opinión y la voluntad, la cual hace posible a su vez (el ejercicio de autonomía política y) una producción legítima de normas" (p. 523). La sociedad civil (concebida como una red de interacciones comunicativas) desde el espacio público y centrada en torno al concepto de los derechos, plantea exigencias a los sistemas económico, político-administrativo 
y político-estatal. Estos poderes creadores de sistemas ${ }^{22}$ son integradores sociales en principio no comunicativos, que se ven sometidos al ordenamiento jurídico autoreflexivo, debido a imperativos discursivos que imponen su conexión con la autodeterminación comunicativa. ${ }^{23}$

De tal forma, Habermas propugna una concepción procedimental de la racionalidad, del Derecho y del proceso democrático. Esta fórmula discursiva sirve a la integración social, porque está sustentada en la interconstrucción de la opinión institucionalizada y de la opinión pública informal en el foro público, enraizada en una sociedad civil políticamente libre e implicada.

La legitimidad es fruto del consenso racional de todos, de la autorregulación racional de los sujetos que son políticamente libres, tal como dice el propio autor "los medios por los que una mayoría llega a ser una mayoría es aquí lo importante" (Habermas, 1998, p. 380). La procedimentalidad legitimatoria propia de la teoría del discurso implica un cambio de paradigma del Derecho. Esta precomprensión discursiva del ordenamiento jurídico y de la 'realidad ideal' que propugna reconoce implícitamente la igualdad de estatus y es lo que fundamenta el sistema de derechos. El derecho de no discriminación permite el funcionamiento de la maquinaria discursiva, y es el soporte de la fundamentación discursiva de todos los demás derechos. Esta afirmación, que requiere identificar un principio sustantivo de no discriminación subyacente a la exigencia racional o procedimental habermasiana, es la que se tratará de demostrar a continuación.

\section{El presupuesto procedimental: la igualdad de estatus o el derecho a no ser discriminado}

Aquí el presupuesto discursivo del 'mejor argumento' se traduce en un derecho a la no discriminación o reconocimiento de un estatus de "iguales" entre los participantes en el discurso o interacción antes, incluso, de la línea de salida dialógica. Aunque el concepto de 'trato de iguales' o trato no discriminatorio está comprendido en el valor 'igualdad', este es sólo un aspecto destacable del valor 'igualdad' y no extensible a todo él, ${ }^{24}$ es decir, no se trata del trato igual o desigual de lo igual

22 Habermas parte de la teoría de sistemas de Niklas Luhmann y defiende la interacción de los mismos. Las diferencias presentes en sus respectivas concepciones sistémicas se encuentran analizadas en Ladeur (1999).

23 Habermas (1998) sostiene que el lenguaje ordinario es el lenguaje común de entendimiento, desempeñando el Derecho una función traductora de éste a los lenguajes especiales propios de otros sistemas (economía, administración, etc.), y afirma: “el Derecho funciona, (...) como un transformador, que es el que asegura que la red de comunicación social ģlobal sociointeğradora no se rompa” (p. 120).

24 No se pretende defender el trato iģualitario de los sujetos más allá de la defensa que haģan los propios sujetos en el ejercicio de su iģual libertad. Es decir, los sujetos como parte de sus proyectos vitales ostentarán un determinado 'sentido de justicia' o criterios de convivencia que será actualizado al defender y confrontar sus propuestas existenciales. 
o desigual, esto sería una cuestión posterior a dilucidar discursivamente, sino de contemplar el discurso como discurso entre iguales. ${ }^{25}$ En palabras de Habermas (1998), "los sujetos jurídicos privados no podrán gozar de iguales libertades subjetivas si ellos mismos, en común ejercicio de su autonomía política, no se aclaran sobre intereses justificados y sobre criterios, y no se ponen de acuerdo sobre cuáles han de ser los aspectos relevantes bajo los que lo igual ha de tratarse de forma igual y lo desigual de forma desigual" (p. 61).

En suma, para poder llegar al mejor argumento es necesario que no exista discriminación en las potencialidades de visión y acción de los sujetos discursivos.

\subsection{Por qué el derecho a no ser discriminado, ¿cómo se infiere?}

El discurso "entre iguales" será lo que rija las normas de la interacción comunicativa. Los motivos se pueden explicar desde las reglas del juego discursivo:

En primer lugar, si el discurso se entiende como autorregulación de todos, resulta obvia la potencial participación o la inclusión de todos. Esto no requiere que los participantes sean de facto iguales, sino que no exista discriminación en la participación de todos o en su capacidad de concurrencia como iguales en la exposición de la pretendida validez de sus proyectos. Habermas (1998), concibe esta participación como "la utilización efectiva de un estatus activo de ciudadano, a través del que el individuo puede ejercer una influencia democrática sobre el cambio de su propio status o situación" (p. 143) ${ }^{26}$.

En segundo lugar, la pretendida validez de las pretensiones debe concebirse, en principio, sin discriminación, puesto que los participantes discursivos son iguales y sus proyectos vitales igualmente válidos. ${ }^{27}$

Después, si la autorregulación de todos se pretende respaldada por el mejor argumento, se tendrá que admitir un igual potencial argumentativo o racional a las

25 Nino (1989) sostiene que "nuestra dignidad como personas se ve menoscabada (...) cuando alguien considera unas y otras [creencias y opiniones] como objeto de tratamiento y no las pone en el mismo nivel que sus propias creencias y decisiones, (...) sentimos que no nos trata como un iģual al neģarnos el status moral que nos distingue a él y a nosotros de las restantes cosas que pueblan el mundo" ( $p$. 289). Por su parte, el profesor Rodríguez-Toubes (1995) afirma "creo plausible que se sitúe en la cúspide valorativa el respeto a un derecho básico (...) derecho a iģual consideración y respeto" (p. 61).

Debe subrayarse que, si la concurrencia tiene como finalidad la interconstrucción de proyectos comunes, cabría preguntarse sobre si los escépticos contribuirían a esa construcción, y en todo caso, cuál sería el signnificado de su silencio discursivo. No parece que se pueda sostener que su silencio no tuviese un impacto en el discurso, sino que sería un silencio que constituiría una opinión. Habermas (1998) considera que los escépticos siempre están dentro de la trama comunicativa quieran ellos o no, aunque sea para sostener la validez de que no quieren participar.

Habermas (1988) afirma: "lo que puede expresarse normativamente son las condiciones necesarias pero generales para una vida (...) que ha de poner a los participantes mismos en situación de realizar las posibilidades concretas de una vida mejor y menos peligrosa según las propias necesidades y conveniencias y según la propia iniciativa" (p. 134). 
pretensiones de cada individuo, lo que presupone el reconocer una igual capacidad racional a los participantes o una racionalidad propia de iguales.

Por último, si la exigencia de racionalidad implica que sólo el mejor argumento, y no otro criterio, pese en la validez de lo consensuado, no caben coacciones que puedan ir en detrimento de la posición de iguales de quienes participan en la deliberación.

Así, la autorregulación discursiva (o consenso) se sustenta en la convicción y atribución de que todos los participantes tienen el mismo estatus, ya que cualquier argumentación discursiva implica aceptar al otro como un igual. Por tanto, el derecho a la no discriminación es un instrumento para la autorregulación. Además de fundamentarse en un cambio en la precomprensión del derecho, al implementarlo se convierte en requisito de la participación discursiva que pondrá en funcionamiento el engranaje en el que se asienta esta comprensión.

\section{2. ¿Cómo se deriva la existencia de derechos del derecho a no ser discriminado?}

De lo dicho hasta ahora se desprende la siguiente tesis:

Primero, el derecho a no ser discriminado es una exigencia racional del engranaje discursivo (o requisito del consenso basado en el mejor argumento).

Segundo, el derecho a no ser discriminado posibilita la posterior construcción discursiva del necesario sistema de derechos ${ }^{28}$ que surge de la aplicación del principio del discurso al Derecho. De este modo, la legitimidad del Derecho depende de la participación discursiva no discriminatoria de los sujetos en los procedimientos jurídicamente institucionalizados y del uso que los mismos decidan hacer de sus derechos políticos. La manera en la que se institucionalizan los consensos democráticos constituye el molde con el que medir la realización de los derechos o su legitimidad. El Derecho no puede obligar a los titulares de los derechos a hacer un determinado uso de los mismos.

\footnotetext{
28 Habermas (1998) sostiene que el principio del discurso (como principio de universalización que implica tener en cuenta el interés de todos por iģual, siendo el criterio decisorio el mejor aróumento) es una reğla de arơumentación y no de acción. El principio democrático dice cómo institucionalizar la opinión y voluntad política discursiva, y ģarantiza el caldo de cultivo de la misma. En suma, a través de un sistema de derechos se rige el procedimiento de producción de normas leǵítimas. Esto se debe a que la normatividad racional, caracterizada por la indeterminación coǵnitiva, la incertidumbre motivacional, y el escaso grado de exiģibilidad, requiere de la complementariedad constructiva y reconstructiva del sistema jurídico (sistema de acción). Este derecho legítimo necesita de los sujetos discursivos, y la determinación de los mismos depende de un sistema de derechos. El requisito discursivo de la autorregulación de todos exiģe derechos/libertades subjetivas iģuales para todos, informando el sistema de derechos. Así, "la ģénesis lóģica de estos derechos constituye entonces un proceso circular (...) en el que el códiģo que es el derecho y el mecanismo para la generación de derecho leǵítimo, es decir el principio democrático, se constituyen cooriģinalmente" (Habermas, 1998, p. 187).
} 
Finalmente, el derecho a no ser discriminado, informador del sistema de derechos, es la base de todo el ordenamiento jurídico, que, a su vez, es lo que regula el poder económico, político y administrativo. La participación discursiva no discriminatoria es la fuente de toda legitimidad, ya que esta justifica el Derecho que racionaliza el poder. ${ }^{29}$

\section{El presupuesto normativo}

Si bien el derecho a una participación discursiva no discriminatoria se concibe como una exigencia racional del procedimiento dialógico consensual, cabe hacerse algunas preguntas y responderlas:

Primero, ¿por qué el procedimiento discursivo asume como exigencia procedimental una participación discursiva no discriminatoria? Es decir, ¿por qué un procedimiento no discriminatorio? Por su virtualidad de crear un espacio para un dialogo no discriminatorio.

Pero, ¿por qué un dialogo no discriminatorio? Porque se presume que todos los sujetos tienen virtualidad dialogante y pretensiones dignas de ser defendidas racionalmente de forma no discriminatoria, es decir, se asume que todos somos sujetos coherentes tras cuyas pretensiones está el pluralismo de proyectos vitales y visiones del mundo.

En último lugar, ¿por qué la virtualidad dialogante de los sujetos implica legitimar la exigencia a ejercerla y a ejercerla no discriminatoriamente ${ }^{30}$ ¿por qué sus pretensiones son dignas de ser defendidas racionalmente de forma no discriminatoria? En suma, ¿por qué exactamente el proceso discursivo descrito o un procedimiento informado por la no discriminación y no otro?

Llegados a este punto, se podría argumentar que aunque Habermas presenta esta exigencia de no discriminación discursiva como exigencia racional del procedimiento, ésta se justifica implícitamente en un principio sustantivo o de justicia que consiste en el igual respeto o no discriminación de los participantes (y de sus proyectos de vida), que hace que el procedimiento discursivo propuesto sea el que es $y$

29 El Derecho presupone al poder estatal que lo hará efectivo, de tal forma que no es suficiente con la leģitimidad del Derecho; el poder estatal de sanción, orģanización y ejecución habrá de ser iģualmente legítimo. Así, la leģitimidad del poder proviene de los circuitos de comunicación, comunicación institucionalizada e informal (poder civil comunicativo proteģido por el sistema de derechos), que informan al Derecho que da al poder forma jurídica (normas constitutivas, rectoras, orģanizativas, y de control). El poder se informa y ģenera comunicativamente atándose, ya que "en la acción comunicativa las razones constituyen también motivos [que determinarán las estrategias y los fines colectivos a perseguir por el poder]" (Habermas, 1998, p. 218). Así, la conexión del poder estatal con el poder comunicativo se explica por la separación de poderes estatales que, a su vez, responde a una distribución racional de poder. Rodríguez-Toubes (1995) formula la cuestión cuando afirma: "creo que para fundamentar los Derechos Humanos por esta vía hay que especificar cómo es que el hecho de poseer competencia comunicativa genera el derecho de reclamar las condiciones para ejercerla" (p. 174). 
no otro. Es decir, aunque Habermas entiende esta exigencia cómo implicación de las prácticas comunicativas, éstas se conciben de tal forma porque sus participantes son caracterizados según las exigencias de un principio de justicia previo.

\subsection{Un principio sustantivo}

Entonces, ¿cuál sería la justificación de este principio sustantivo? Aceptando la teoría de las necesidades básicas ${ }^{31}$ como fundamento de los Derechos Humanos (aunque utilizando los vocablos potencialidades/capacidades), se asume el principio/derecho de no discriminación como principio de justicia, y se intenta a continuación responder acerca del fundamento de tal principio, tras una breve aclaración sobre el uso de los términos mencionados.

Los seres humanos tenemos potencialidades que queremos desarrollar o convertir en capacidades. Las necesidades surgen de la imposibilidad de desarrollar nuestras potencialidades en capacidades. De esta forma, se pueden plantear las capacidades humanas como la otra cara de las necesidades. Esto se debe a que una necesidad satisfecha implica una oportunidad para actualizar una potencialidad de la existencia humana, es decir, convertirla en una capacidad. Y, a la inversa, una capacidad mermada hace surgir una necesidad. Es decir, si no existe la capacidad potencial no podrá devenir la necesidad. La potencialidad vital practicable o capacidad que deriva de la no discriminación sería, vista desde otro ángulo, la satisfacción de la necesidad de autonomía (entendida esta en sentido amplio como capacidad de acción). ${ }^{32}$

Volviendo a la fundamentación del principio de justicia asumido, la no discriminación (o igual libertad de participación en la constitución de lo social), es instrumental a la consecución del fin vida. La no discriminación es para todos los seres humanos una necesidad objetiva o empírica y universal (ya que sirve a un fin no contingente, por lo que la necesidad también lo es) y, por todo lo anterior, es moralmente relevante.

La justificación de este principio de justicia o derecho a no ser discriminado reside en que la exigencia fundamental de no ser discriminado es condición para

31 Para una clasificación sobre necesidades consideradas básicas, absolutas o categóricas (aquellas supeditadas a fines no dependientes de las intenciones, deseos o preferencias de los sujetos, y cuya no satisfacción comporta un daño grave), ver Doyal y Goung, (1994, pp. 240-241). Heller (1996) destaca la no intencionalidad de las necesidades y las define como "las situaciones o estados siempre predicados de una persona y que tienen un carácter insoslayable para ellas” (p. 55).

32 A propósito de la preferencia por los términos 'capacidades' y 'potencialidades', señalaremos que ésta (quizás, debido al uso vulgar de los términos) se debe: primero, a su mejor adecuación con el carácter inmaterial de la exiggencia de no discriminación, frente a la expresión 'necesidades', que parece asociarse más con la obtención o tenencia de cosas materiales. Seģundo, a que se aleja de un mundo lleno de satisfactores funcionales de unas necesidades materiales creadas (el 'poseer bienes' o consumo) que, en mi opinión, nada tienen que ver con las necesidades humanas intrínsecas, aunque en nuestra época del consumismo, de la tecnología, del aburrimiento y de la prisa, lo podamos percibir de otra manera. 
que se realice otro fin: vivir, más concretamente, vivir la vida 'buena' elegida o construir un curso de acción vital. ${ }^{33} \operatorname{Raz}(1986)$ concreta la autodeterminación en la capacidad de las personas de controlar su propio destino, a través de sucesivas decisiones a lo largo de sus vidas (p. 369). Lo anterior presupone la existencia del ser humano como agente moral (Zimmerling, 1990, p. 39) y de la vida como su fin último. En palabras de Nieburh (2001) "los hombres toman conciencia de sí mismos (...) [esto] conlleva la necesidad de preservar y prolongar la vida" (p. 41).

La justificación del principio/derecho a no ser discriminado conlleva el considerar al ser humano como ser autónomo o con capacidad de tener un proyecto de vida determinado por el que regir su propia existencia $y$, por tanto, se hace necesario justificar por qué la potencialidad de autonomía innata del ser humano es moralmente relevante.

La potencialidad de autorrealizarse ${ }^{34}$ (que es posibilitada por la no discriminación del proyecto de vida individual), es elemento constitutivo o contenido del fin de carácter último o no contingente: vivir. Respecto a la necesidad humana de tener proyectos vitales, Frankl, un famoso psiquiatra austriaco, sostiene que estos objetivos vitales dan sentido a la vida, porque sirven para la autoconstrucción de la vida personal y social. Según este autor, el ser humano tiene una 'necesidad de orientación' o de sentido, generando su ausencia desubicación o falta de control, falta de responsabilidad individual, apatía o confusión existencial, un dejarse ir, la enfermedad psíquica y física e, incluso, la muerte. ${ }^{35}$

33 Nino (1989) sostiene que "lo que hace moralmente relevantes a las decisiones de un individuo es que su materialización forma parte de un cierto plan de vida" (pp. 291-292), y esto conduce a la responsabilidad. Nino (1990) afirma: “autorealización (...) [o] realización autónoma, o sea, una realización de la que es autor el propio individuo concernido. En el centro de esta concepción del bien personal, está la idea de capacidades (...) El individuo se autorealiza en la medida en que actualiza en forma plena y equilibrada sus diversas capacidades (...) lo que es propio de cada individuo es el curso que da a su vida, ejercitando con sus diversos actos una u otra capacidad" (p. 31). El mismo autor define el principio de autonomía de la persona como libre opción o "libre elección individual de planes de vida" (Nino, 1989, p. 204). Otro concepto de realización autónoma o autonomía que destaca la autoría o control del sujeto implicado, dice: "autonomía quiere decir: enumerar por derecho propio las múltiples alternativas de acción, seleccionar las más adecuadas, disponerlas según orden de prioridades y de llevarlas a cabo. Además, por derecho propio, organizar y estipular las relaciones materiales y no-materiales con el ambiente social” (Thimm, 1990, p. 96).

Victor Frankl, un psiquiatra austriaco judío, estuvo prisionero en varios campos de concentración nazi y observó que muchos de los prisioneros que morían en cautiverio estaban sometidos a menores dificultades y sufrimiento que otros que sobrevivían, caracterizando a estos últimos una visión de futuro para ellos mismos o un 'sentido de la vida' que les proporcionaba fuerzas para no dejarse morir. A raíz de sus observaciones, Frankl inventó la logoterapia (tratamiento psicológico) y sostuvo que: 1) dentro de las estructuras psicolóģicas de la personalidad que jueģan un papel crucial en la autorregulación y, por tanto, en los valores ético-morales, está el sentido de la vida. 2) El sentido de la vida esta conformado por subsistemas de motivos que coexisten y tiene la suficiente estabilidad y potencial movilizador de los recursos psicológicos como para expresarse en actividad interna (psíquica) y externa en la mayoría de las circunstancias. 3) El sentido de la vida es lo que justifica un 'estar en el mundo' o existencia de un individuo analizada en su totalidad ante sus propios ojos. Así, las preguntas intrínsecamente humanas como: ¿quiénes somos?, ¿de dónde venimos?, ¿a dónde vamos?, ¿qué sentido tiene mi vida?, 
Así, no ser discriminados nos capacita para ser agentes morales, presupuesto de la acción moral que nos permite perseguir nuestro último objetivo: vivir. ${ }^{36}$ Esta potencialidad de vivir la vida que uno elige es constitutiva de nuestra capacidad de acción, lo que ineludiblemente permite que un sujeto pueda considerarse y ser considerado por otros agente moral, ${ }^{37}$ capaz de hacer y capaz de ser responsable de su acción vital. ${ }^{38}$ En otras palabras, la elección de un proyecto de vida personal (autonomía privada) va de la mano de la elección de vida junto a los demás (autonomía pública $)^{39}$.

La discriminación o capacidad menoscabada de construir y participar en un proyecto vital es considerada un perjuicio universalizable, debido a que si el fin de vivir es no contingente, la capacidad instrumental a ese fin, y su menoscabo, también será no contingente y universalizable. Además, el daño a las capacidades inherentemente humanas será un daño grave, ya que, según De Lucas y Añon (1990) "puede ocasionar una 'destrucción, desintegración o no existencia de un ser humano" (p. 58). ${ }^{40}$

Pero, ¿sería la constatación de la existencia de esta potencialidad y/o el daño que conlleva su menoscabo suficiente razón para exigir que se proteja jurídicamente, creando obligaciones para terceros? Para responder a esta cuestión es necesario

¿para qué existo? y ¿para qué estoy en el mundo? serán contestadas por cada sujeto para determinar su curso vital. La contestación (que será individual, única e irrepetible) nadie podrá darla con mayor conocimiento que el individuo implicado, y nadie podrá responderlas por ese individuo. A propósito de la anterior afirmación, no se debe pasar por alto que el individuo por su propia condición de ser humano (pensante-autoreflexivo, afectivo, y conductual) es producto de la interacción social, y que su fin es la adaptación-integración social. Así, el encontrar sentido a la vida depende de múltiples factores que, en definitiva, tienen que ver con la autorrealización (es decir, con la satisfacción personal sumada al hecho de poder trascender en el ámbito social o de ayudar al bienestar de otros, a través de contribuciones a la sociedad y a la humanidad en ơeneral). Este sentido será el núcleo esencial de la identidad o individualidad de la persona, ya que su carácter de autorregulación rectora-inductora (o de valores personales o ética privada, de la personalidad o de la identidad), será el 'norte' a partir del cual se siente, piensa y actúa. Por tanto, los proyectos vitales son necesarios para vivir. Ver Frankl, (1992, pp. 60, 74-88 y 104-106; 1957, pp. 38-130 y 1982, pp. 17-46 y pp. 113-125).

36 De esta manera, se concibe el diseño de una coreografía vital propia como instrumento humano que permite la supervivencia o existencia. Frankl (1992) afirmó: “El prisionero que había perdido la fe en el futuro- su futuro- estaba sentenciado. Con su perdida de confianza en el futuro él también perdía su soporte espiritual; se dejaba deteriorar y se volvía propenso a la decadencia mental y física... él simplemente se daba por vencido [muerto]" (pp. 82-83). Rand (2003) consideró al hombre un fin en sí mismo y a su búsqueda de su propio interés racional y de su propia felicidad el más alto propósito moral de su vida.

37 De Asís (2001) afirma que "el marco moral implica pues la defensa de una idea de individuo como sujeto moral lo que supone considerar a este como ser dotado de capacidad de elección...y con una vida orientada hacia el logro de planes de vida..." (p. 35).

38 Frankl sostiene que el 'sentido de la vida' define lo que se es y lo que no se es, y por tanto, la responsabilidad. Así, la voluntad de siǵnificado y propósito, y la responsabilidad individual se conciben como la motivación básica de la vida humana (Frankl, 1992, pp. 87 y 104).

39 Niebuhr (2001) va más allá al afirmar: "No existe la posibilidad de trazar una línea divisoria clara entre la voluntad de vivir y la voluntad de ejercer poder...el espíritu humano [es] mezcla de miedo a la extinción y el amor del poder" (p. 42).

40 En el mismo sentido, ver Thomson (Thomson, 1987). 
acudir a De Lucas y Añon, (1990) “dar razón de por qué algo ha de ser realizado o satisfecho en orden a que el sujeto de la necesidad cumpla su función como ser humano" (p. 59). Esta exigencia entendida como constitutiva de nuestra capacidad de acción, a lo que se añadiría el concepto de daño o lesión universalizable, implicaría el tener que tomar decisiones racionales al respecto. Tal y como afirma Krause (citado en Fernández Querol, 2000):

Dado que el hombre es un ser racional (...) así pues la condición humana también puede ser denominada condición racional, y en este sentido decirse que su condición es vivir conforme a la razón (...) conforme a la racionalidad. El derecho (...) no es un fin en sí mismo, sino que es condición... para que el hombre pueda desarrollar su esencia como hombre (...) es pues evidente (...) que las condiciones de la vida racional, esto es, todas aquellas condiciones bajo las cuales un hombre puede desarrollar su vida (...) conforme a la razón, deben ser aceptadas y reconocidas como el contenido del derecho. Aún más, estas condiciones no constituyen sólo la materia jurídica, sino (...) el fundamento jurídico. (pp. 87-88) ${ }^{41}$

Es decir, las potencialidades humanas, como son instrumentos del fin vida (y ésta es la clave, vivir es lo relevante), serían razones a tomar en cuenta y fuente de justificación para una protección jurídica. La respuesta plausible sería reconocer un derecho que implicaría un deber positivo de todos. Así, este deber se justificaría en el carácter universalizable de esta exigencia, y en que es moralmente relevante, ya que es presupuesto de cualquier acción moral, y por tanto, de cualquier moral posible. ${ }^{42}$

Así, la necesidad vital de la igual libertad para elegir un proyecto de vida aporta razón suficiente para exigir el diálogo no discriminatorio en el cual confrontar diferentes visiones del mundo y protegerlas con los medios que proporciona el Derecho.

\section{Los destinatarios del derecho}

El derecho a no ser discriminado, tal y como se concibe en estas páginas, se atribuiría a todos los agentes morales, es decir, prima facie a todos los seres humanos, y derivaría de la capacidad comunicativa de los sujetos o de su agencia moral.

41 Y continúa: "así, el ser humano tendría el derecho a exiģir que se proteģieran las mencionadas condiciones y esta protección exiģiría del hombre realizar, en su medida, la totalidad de las condiciones libres de la vida racional para todos y cada uno de aquellos que con él conviven" (Krause citado por Fernández Querol, 2000, p. 88).

42 De Asís (2001), refiriéndose a la capacidad de elección de los seres humanos, afirma: "la libertad de elección constituye un dato empírico pero a su vez [es] presupuesto de cualquier reflexión moral” (p. 32). 
Se identifica quiénes serán sujetos del discurso y, por tanto, titulares del derecho a no ser discriminados por medio de las condiciones que recíprocamente presuponen los participantes en el discurso, desde las que se desprenden las características de los sujetos discursivos. El reconocimiento de la capacidad de sostener y orientar sus acciones por pretensiones de validez, implica que se trata de seres racionales. Al identificar que el consenso se basa en el reconocimiento intersubjetivo de pretensiones, y de que los seres humanos asumirán las obligaciones derivadas de este mismo, se entiende que son individuos sociales y normativos. Así, los sujetos discursivos con derecho a no ser discriminados serán personas racionales, sociales y morales, es decir, seres humanos.

En relación con lo anterior, podría decirse que no sólo serán sujetos discursivos con derecho a no ser discriminados los que actualmente ostenten tales características o facultades y hagan uso de ellas, sino también aquellos que las ostentan y no las utilizan dialógicamente, así como aquellos que podrán ostentarlas en el futuro. Es decir, no sólo se reconocen aquí como titulares del derecho los actuales participantes discursivos, sino también los potenciales participantes, incluidos los escépticos discursivos, pues como afirma Nino (1989) "Es obvio que la capacidad es compatible con su no actualización" (p. 360). ${ }^{43}$

La anterior conclusión se debe a que, en realidad, tanto el procedimiento del discurso, como el hablar de potencialidades que proporcionan razones para proteger a las mismas, presupone unos agentes morales, y éstos no son sino los seres humanos, es decir: todos. Todos vivimos y manifestamos preferencias vitales, lo relevante es que ostentamos las características mencionadas, independientemente del grado y de que se lleguen a realizar o no. ${ }^{44}$

\subsection{Alcance y contenido}

Una vez establecido el fundamento del derecho a la no discriminación o el derecho a la atribución de un estatus de iguales con fines discursivos en el que concretar las necesidades/capacidades humanas dignas de protección jurídica (la determinación de los derechos), cabe preguntarse sobre el alcance y contenido de este derecho.

El cambio de paradigma y la comprensión procedimental del Derecho, al requerir el mutuo reconocimiento de sujetos discursivos de un mismo estatus en el discurso,

\footnotetext{
43 Nino (1989) sostiene que las condiciones que imposibilitan el ejercicio de la capacidad para que esta continué siendo considerada como tal, deberán ser salvables por el desenvolvimiento normal de las cosas, por la aplicación de la tecnología actual, o con prácticas institucionales o sociales accesibles.

44 Según Dahl (2008), la iģualdad intrínseca de la persona conlleva a que ninģuna es superior a otra y que se debe dar iģual consideración a los intereses de cada persona, esto frente a la evidente existencia de desiģualdades, pues, como advirtió Rawls, no existe ningún rasģo con respecto a que las personas sean iguales (p. 19). Ver también Rawls (1995, p. 458).
} 
conectan la autonomía privada con la pública (autoconfiguración de la comunidad jurídica). De esta forma, el derecho a la no discriminación en la participación en los procesos de formación de la opinión y voluntad discursiva sería el derecho a una existencia social discursiva no discriminatoria. Así, todos los derechos (o la protección de las potencialidades humanas respecto a las que se deliberaría) derivan en última instancia del derecho a no ser discriminado ejercido discursivamente. El sistema de derechos garantizará las condiciones necesarias para la autorregulación legítima. Por tanto, para Habermas (1998) "la cooriginalidad de autonomía privada y autonomía pública se muestra sólo cuando desciframos y desgranamos en términos de teoría del discurso la figura de pensamiento que representa la "autolegislación", figura conforme a la cual los destinatarios son a la vez autores de sus derechos" (p. 169). Las claves del paradigma discursivo son la concepción relacional o intersubjetiva de los derechos y la estructura comunicativa de la autoregulación, que vinculan de manera inseparable la esfera privada con la pública. Informar todo el ordenamiento jurídico sería, por tanto, el alcance y contenido del derecho a no ser discriminado.

\section{Conclusión}

La fundamentación de la idea de los Derechos Humanos viene dada por la consideración de un principio de justicia que se concreta en el derecho a no ser discriminado, constitutivo de la acción moral del sujeto, cuya violación implica un daño vital universalizable y lo que sería razón suficiente para fundamentar los derechos que deberían concretarse de acuerdo a un procedimiento informado por este mismo principio (procedimiento discursivo consensual).

En el foro discursivo, los sujetos expondrían sus pretensiones y plantearían aquello que perciben como una necesidad, así como la validez de las razones que justifiquen la exigencia de su satisfacción. Si bien las pretensiones de los participantes vendrían determinadas por sus respectivas concepciones del mundo y de sí mismos a la vez, las exigencias racionales del debate impondrían un distanciamiento de los sujetos discursivos respecto de sus visiones particulares, lo que posibilitaría concebir racionalmente, por, entre y para extraños ${ }^{45}$ la mejor solución normativa. Así, este planteamiento no discriminatorio de lo que potencialmente podría considerarse una necesidad a satisfacer $y$, su sometimiento a debate o argumentación racional, permitiría alcanzar consensos sobre los cuales construir un sistema de derechos válido o legítimo para satisfacer, según lo entendiesen los

45 Habermas (1999) afirma "la formación de la opinión y la voluntad estructurada democráticamente posibilita un acuerdo normativo racional también entre extraños” (p. 116). 
sujetos discursivos (es decir, históricamente), ${ }^{46} \mathrm{y}$ lo moldearan las necesidades básicas o condiciones de existencia específicamente humanas. En consecuencia, el sistema de derechos constituiría el guion de la autocoreografía diseñada por y para la comunidad discursiva. Esto no es concebible sino allí donde se dé un gobierno democrático deliberativo, y sujetos cuya existencia sea viable, lo que presupone el reconocimiento no discriminatorio de los mismos. ${ }^{47}$

El siguiente gráfico ilustra esta relación visualmente.

$$
\longmapsto \quad \begin{gathered}
\text { Principio de } \\
\text { no discriminación }
\end{gathered}
$$

Proyectos Vitales

$\uparrow \quad$ Derechos

Autorregulación

Esta comunidad discursiva podría aspirar a vincular la concepción de la vida como iguales y la participación política a favor de una sociedad justa a través de la autodeterminación, pues lo contrario significaría la muerte Grosswald (1994) "no sólo del hombre, sino del concepto de hombre" (p. 47). ${ }^{48}$

\section{Referencias}

Alexi, R. (1993). Teoría de los derechos fundamentales. Madrid: Centro de Estudios Constitucionales.

Alexi, R. (2003). La fundamentación de los Derechos Humanos en Carlos S. Nino Doxa, 26, 173-201.

Atienza, M. (2001). El sentido del Derecho. Barcelona: Ariel.

Ávila, H. (2011). Teoría de los Principios. Madrid: Marcial Pons.

46 Como señala Cordero (2009), “el derecho es una realidad cultural (...) un fenómeno que muta o se transforma" (p. 12).

47 De la constatación de la existencia de la capacidad/necesidad humana de autonomía que sirve al fin vida, no cabría derivar un catálogo de derechos, ya que ésta es inseparable de las peculiaridades de los seres humanos. Es decir, el reconocimiento del derecho de no discriminación sirve precisamente para la construcción de un foro público en el que todos defiendan sus distintas visiones del mundo (o particularidades que no son transmisibles a otros) y en éste se logran los consensos que fundamentarán los derechos.

48 En el mismo sentido, Mate (2002) sostiene que "Auschwitz (...) obliga a revisar la fundamentación moderna de la moralidad, basada en la dignidad y el respeto de (sí) [la especie humana]" (p. 14). 
Barranco Avilés, M. C. (2000). La teoría jurídica de los derechos fundamentales. Madrid: Dykinson.

Barker, P. (Comp.) (2000). Vivir como iguales. Apología de la justicia social. Barcelona: Paidos.

Bertolino, R. (1999). La cultura moderna de los derechos y la dignidad del hombre. Derechos y Libertades: Revista del Instituto Bartolomé de las Casas, (07), 131-139.

Bobbio, N. (1993). Igualdad y Libertad. Barcelona: Paidós.

Bobbio, N. (1994). Elogio de la templanza y otros escritos morales. Madrid: Temas de Hoy.

Boeckenfoerde, E. W. (1991). Staat, Verfassung, Demokratie, Studien zur Verfassungstheorie und zum Verfassungsrecht. Frankfurt, Suhrkamp.

Calsamiglia, A. (1989). Sobre el principio de igualdad. En J. Muguerza (Ed.), El fundamento de los Derechos Humanos (pp. 97-110). Madrid, Debate.

Capotorti, F. (1991). Estudio sobre los derechos de las personas pertenecientes a minorías étnicas, religiosas o lingüísticas. Naciones Unidas.

Carta de Derechos Fundamentales de la Unión, DOCE 2000/C 364/01, de 18 de diciembre de 2000. Recuperado de http://www.europarl.europa.eu/charter/ pdf/text_es.pdf

Comité para la Eliminación de la Discriminación contra la Mujer de la ONU. Recomendación General 19, La violencia contra la mujer, U.N. Doc. HRI/ GEN/1//Rev.1 (1994). Recuperado de http://confdts1.unog.ch/1\%20SPA/ Tradutek/Derechos_hum_Base/CEDAW/00_4_obs_grales_CEDAW.html

Constitución Española, BOE n. 311, de 29 de diciembre de 1978. Recuperado de https://www.boe.es/diario_boe/txt.php?id=BOE-A-1978-31229

Contreras Peláez, F. J., (2000). La idea de igualdad en el pensamiento político de Kant. Derechos y Libertades, 9, 225-283.

Convención Interamericana para Prevenir, Sancionar y Erradicar la Violencia contra la Mujer o "Convención de Belém do Pará", de 9 de junio de 1994, en vigor el 5 de marzo de 1995, 33 I.L.M.1534 (1994). Recuperado de http:// wwwl.umn.edu/humanrts/oasinstr/Swomen.html 
Convención Internacional sobre la Eliminación de todas las Formas de Discriminación Racial, 660 U.N.T.S. 195, entrada en vigor 4 de enero de 1969. Recuperado de http://www1.umn.edu/humanrts/

Convención relativa a la lucha contra las discriminaciones en la esfera de la enseñanza, 429 U.N.T.S. 93, entrada en vigor 22 de mayo de 1962. Recuperado de http://www1.umn.edu/humanrts/

Convención sobre la Eliminación de todas las Formas de Discriminación contra la Mujer, A.G. res. 34/180, 34 U.N. GAOR Supp. (No. 46) p. 193, ONU Doc. A/34/46, entrada en vigor 3 de septiembre de 1981. Recuperado de http:// www1.umn.edu/humanrts/

Convenio Europeo sobre Prevención y Lucha contra la Violencia contra las Mujeres y la Violencia Doméstica, de 11 de mayo de 2011, CETS N. 210. Recuperado de https://rm.coe.int/CoERMPublicCommonSearchServices/DisplayDCTMContent?documentId=0900001680462543

Convenio sobre la discriminación -empleo y ocupación-, (ILO No. 111), 362 U.N.T.S., entrada en vigor 15 de junio de 1960. Recuperado de http:// www1.umn.edu/humanrts/

Cordero Quinzacara, E., (2009). Los principios y reglas que estructuran el Ordenamiento Jurídico chileno. Ius et Praxis. 15(2), 11-49.

Dahl, R. A., (2008). La igualdad política. Buenos Aires: Fondo de Cultura Económica.

De Asís, R. (2001). Sobre el concepto y el fundamento de los Derechos: Una aproximación dualista. Cuadernos Bartolomé de las Casas, 17, 23-ss.

De Castro Cid, B., \& Escalopa Martínez, G. (1997). Problemas básicos de la Filosofía del Derecho: Desarrollo Sistemático. Madrid: Universitas.

De Lucas, J., (1994). El desafío de las fronteras. Madrid: Temas de Hoy.

De Lucas, J., (1996). Puertas que se cierran. Europa como fortaleza. Barcelona: Icaria.

De Lucas, J. y Añon, M. J., (1990). Necesidades, razones y derechos. Doxa: Cuadernos de filosofía del Derecho 7, 55-81.

Declaración sobre la Eliminación de la Violencia contra la Mujer, A. G. Res. 48/104, de 20 de diciembre de 1993. Recuperado de http://www.un.org/en/ga/68/ resolutions.shtml 
Declaración sobre la Eliminación de Todas las Formas de Intolerancia y Discriminación fundadas en la Religión o las Convicciones, A.G. res. 36/55, 36 U.N. GAOR Supp. (No. 51) p. 171, ONU Doc. A/36/684 (1981). Recuperado de http://www1.umn.edu/humanrts/

Doyal, L., y Goung, I. (1994). Teoría de las Necesidades Humanas. Madrid: Icaria.

Dworkin, R. (1989). Los Derechos en Serio. Barcelona: Ariel.

EC, CM/Rec (2002) 5, de 30 de abril de 2002. Recuperado de http://www.msssi. gob.es/ssi/igualdadOportunidades/internacional/consejoeu/CAHVIO.pdf

Fernández Querol, F., (2000). La filosofía del Derecho de K. CH. F. Krause. Con un apéndice sobre su proyecto europeísta. Madrid: Universidad Pontificia Comillas.

Frankl, E. V. (1957). Psicoanálisis y existencialismo. México, D.F: Fondo de Cultura Económica.

Frankl, E. V. (1982). Psicoterapia y humanismo: ¿tiene un sentido la vida? México, D.F: Fondo de Cultura Económica.

Frankl, E. V. (1992). Man's Search for Meaning an Introduction to Logotherapy. Boston: Beacon Press.

Grosswald Curran, V. (1994). Deconstruction, Structuralism, Antisemitism and the Law. Boston College Law Review, 36, 1-52.

Habermas, J. (1987). Teoría de la acción comunicativa, Tomo II, Crítica de la razón funcionalista. Madrid: Taurus.

Habermas, J. (1988). Ensayos Políticos. Barcelona: Península.

Habermas, J. (1996). Anhang zu Faktizitaet und Geltung. Replik auf Beitraege zu einem Symposion der Cardozo Law School, Die Einbeziehung des Anderen. Studien zur politischen Theorie. Frankfurt: Suhrkamp.

Habermas, J. (1998). Facticidad y Validez. Sobre el derecho y el Estado democrático de derecho en términos de teoría del discurso. Madrid: Trotta.

Habermas, J. (1999). La inclusión del otro. Estudios de teoría política. Barcelona: Paidós.

Heller, A. (1996). Una revisión de la Teoría de las Necesidades. Barcelona: Paidós.

Junquera, R. (2002). La Fundamentación de los Derechos Humanos: Un intento de Sistematización. Derechos y Libertades, (11), 399-429. 
Kant, I. (1957). Grundlegung zur Metaphysik der Sitten. Hamburg: Felix Meiner.

Ku, C., \& Diehl, P. F. (1998). International Law Classic and Contemporary Readings. Colorado: Lynne Rienner Publishers.

Ladeur, K-H. (1999). The Theory of Autopoiesis as an Approach to a Better Understanding of Postmodern Law. Florencia: European University Institute.

Laporta, F. (1987). Sobre el concepto de Derechos Humanos. Doxa: Cuadernos de filosofía del Derecho,(4), 23-46.

Lukes, S. (1975). El individualismo. Barcelona: Península.

Mate, R. (2002). La singularidad de Auschwitz. El País. Recuperado de http://elpais.com/diario/2002/04/22/opinion/1019426408_850215.html.

Montero, J. (2006). La Concepción de la democracia deliberativa de C. Nino: ¿Populismo moral o elitismo epistemológico? Doxa: Cuadernos de filosofía del Derecho, (29), 319-331.

Monserrat, J., \& Abad, A. (2009). Principio de Discurso y Democracia Directa: Faktizitaet und Geltung y la Obra de B. Ackerman. Doxa: Cuadernos de filosofía del Derecho, 32, 605-626.

Morell, A. (2010). La posición del Tribunal Europeo de Derechos Humanos sobre la custodia compartida de hijos no matrimoniales. Revista Chilena de Derecho de Familia, (2), 241-266.

Naimark, N. M. (2001). Fires of Hatred. Ethnic Cleansing in the Twentieth-Century Europe. Cambridge: Harvard University Press.

Niebuhr, R. (2001). Moral Man \& Immoral Society. A Study in Ethics and Politics. Louisville: Jonh Knox Press.

Nino, S. C. (1989). Ética y Derechos Humanos. Un ensayo de fundamentación. Barcelona: Ariel.

Nino, S. C. (1990). Autonomía y necesidades básicas. Doxa: Cuadernos de filosofía del Derecho, (7), 21-34.

OSCE, Preventing and Combating Violence Against Women, MC. DEC 15/05, recuperado de http://www.osce.org/resources

Perez Luño, A. E. (1989). Sobre los valores fundamentadores de los Derechos Humanos. En J. Muguerza (Ed.). El fundamento de los Derechos Humanos, (pp. 279-288). Madrid: Debate. 
Prono, S. (2013). Moral, Política y Derecho. La ética del discurso y sus aportes al Estado democrático de derecho. Universitas, (17), 47-69.

Protocolo Adicional a la Carta Africana de DDHH y de los Pueblos sobre los Derechos de la Mujer en África, de 11 de julio de 2003, entró en vigor el 25 de noviembre de 2005. Recuperado de http://www.achpr.org/files/instruments/women-protocol/achpr_instr_proto_women_eng.pdf

Rand, A. (2003). La Rebelión de Atlas. Buenos Aires: Grito Sagrado.

Rawls, J. (1995). Teoría de la justicia. México, D.F: Fondo de Cultura Económica.

Rawls, J. (1993). Political Liberalism. Nueva York: Columbia University Press.

Raz, J. (1986). The Morality of Freedom. Londres: Oxford University Press.

Report of the International Law Commission on its 2454th meeting, ILC (Sess. 48) (A/48/10) "Draft Code of Crimes Against the Peace and Security of Mankind, en Yearbook of the International Law Commission, vol. II (2), 1996. Recuperado de http://www1.umn.edu/humanrts/

Rodríguez-Toubes Muñiz, J. (1995). La razón de los derechos. Perspectivas actuales sobre la fundamentación de los derechos humanos. Madrid: Tecnos.

Roldán Barbero, J. (2008). El Nuevo Panorama de la Paz y la Seguridad Internacionales y su Reglamentación Jurídica. En D. J. Liñán Nogueras, \& Roldán Barbero, J. (Eds.). El Estatuto Jurídico de las Fuerzas Armadas Españolas en el Exterior, (pp. 13-38). Madrid: Plaza y Valdés.

Rome Statue of the International Criminal Court, U.N. Doc.A/CONF.183/9*, 1998. Recuperado de http://www.un.org/law/icc/index.html

Rousseau, J-J. (1997). Segundo discurso: sobre el origen y los fundamentos de la desigualdad entre los hombres y otros escritos. Madrid: Tecnos.

SAARC, Convention on Preventing and Combating Trafficking in Women and Children for Prostitution, de 5 de enero de 2002. Recuperado de http:// www.saarc-sec.org/userfiles/conv-traffiking.pdf

Thematic Study on the Issue of Violence Against Women and Girls and Sisability. Report of the Office of the United Nations High Commissioner for Human Rights, UN Doc. A/HRC/20/05, de 30 de marzo de 2012. Recuperado de www.ohchr.org 
Thimm, A. (1990). Necesidades básicas y derechos humanos. En Doxa: Cuadernos de filosofía del Derecho, (7), 83-98.

Thomson, G. (1987). Needs. Londres: Routledge.

Vargas-Machuca Ortega, R. (2002). ¿Repensar o rehacer? El País.

Vega Franco, M. (1984). El tráfico de esclavos con América (Asientos de Grillo y Lomelín, 1663-1674). Sevilla: Escuela de Estudios Hispano-Americanos de Sevilla.

Zagrebelsky, G. (1995). El Derecho Dúctil. Ley, Derechos, Justicia. Madrid: Trotta.

Zimmerling, R. (1990). Necesidades básicas y relativismo moral. Doxa, Cuadernos de filosofía del Derecho, (7), 35-54.

Zuñiga Fajuri, A., Aguilera Bertucci, D., \& Vásquez Bravo, A. (2007). Lejos del Poder. Hacia la implementación de una ley de cuotas en Chile. Revista de Derecho, 20 (2), 9-30. 